Check for updates

Cite this: Chem. Sci., 2019, 10, 5133

๑ All publication charges for this article have been paid for by the Royal Society of Chemistry

\section{Solid-solution alloy nanoparticles of a combination of immiscible Au and Ru with a large gap of reduction potential and their enhanced oxygen evolution reaction performance $\uparrow$}

\author{
Quan Zhang, ${ }^{a}$ Kohei Kusada, (D) *a Dongshuang Wu, (D) a Naoki Ogiwara, ${ }^{a}$

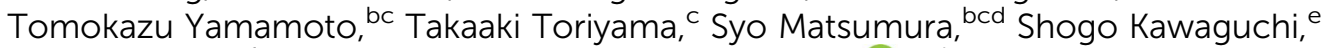 \\ Yoshiki Kubota, ${ }^{f}$ Tetsuo Honma ${ }^{\mathrm{e}}$ and Hiroshi Kitagawa (D) *ad
}

\begin{abstract}
$\mathrm{Au}$ and $\mathrm{Ru}$ are elements that are immiscible in the bulk state and have the largest gap in reduction potential among noble metals. Here, for the first time, $\mathrm{Au}_{x} \mathrm{Ru}_{1-x}$ solid-solution alloy nanoparticles (NPs) were successfully synthesized over the whole composition range through a chemical reduction method. Powder X-ray diffraction and scanning transmission electron microscopy coupled with energy-dispersive $\mathrm{X}$-ray spectroscopy showed that $\mathrm{Au}$ and $\mathrm{Ru}$ atoms are homogeneously mixed at the atomic level. We investigated the catalytic performance of $\mathrm{Au}_{x} \mathrm{Ru}_{1-x} \mathrm{NPs}$ for the oxygen evolution reaction, for which $\mathrm{Ru}$ is well known to be one of the best monometallic catalysts, and we found that even alloying with a small amount of Au could significantly enhance the catalytic performance.
\end{abstract}

Accepted 11th April 2019

DOI: $10.1039 / \mathrm{c} 9 \mathrm{sc} 00496 \mathrm{c}$

rsc.li/chemical-science
Received 28th January 2019

\section{Introduction}

Noble metals (Ru, Rh, Pd, Ag, Os, Ir, Pt, and Au) show their own unique properties and excellent performance as catalysts, ${ }^{\mathbf{1 - 4}}$ despite being minor elements and expensive. They are used as nanoparticles (NPs) for industrial applications; for example, Ru is well known for ammonia synthesis, ${ }^{5-7} \mathrm{Rh}$ is used for $\mathrm{NO}_{x}$ purification of car exhaust, ${ }^{\mathbf{8} 9}$ and $\mathrm{Au}$ is used as an oxidative esterification catalyst. ${ }^{\mathbf{1 0 - 1 3}}$ On the other hand, noble metal alloy NPs have received much attention during the past few decades, because they show synergetic properties derived from each constituent metal. ${ }^{\text {14-19 }}$ Among noble metal alloy NPs, solidsolution alloy NPs, in which different metals are randomly mixed at the atomic level, are more promising than other types of alloys such as the core-shell or segregated type to

${ }^{a}$ Division of Chemistry, Graduate School of Science, Kyoto University, KitashirakawaOiwakecho, Sakyo-ku, Kyoto 606-8502, Japan.E-mail: kusada@kuchem.kyoto-u.ac.jp; kitagawa@kuchem.kyoto-u.ac.jp

${ }^{b}$ Department of Applied Quantum Physics and Nuclear Engineering, Kyushu University, 744 Motooka, Nishi-ku, Fukuoka 819-0395, Japan

'The Ultramicroscopy Research Center, Kyushu University, Motooka 744, Nishi-ku, Fukuoka 819-0395, Japan

${ }^{d}$ INAMORI Frontier Research Center, Kyushu University, Motooka 744, Nishi-ku, Fukuoka 819-0395, Japan

eJapan Synchrotron Radiation Research Insitute (JASRI), SPring-8, 1-1-1 Kouto, Sayocho, Sayo-gun, Hyogo 679-5198, Japan

${ }^{f}$ Department of Physical Science, Graduate School of Science, Osaka Prefecture University, 1-1 Gakuen-cho, Naka-ku, Sakai, Osaka 599-8531, Japan

$\dagger$ Electronic supplementary information (ESI) available. See DOI: $10.1039 / \mathrm{c} 9 \mathrm{sc} 00496 \mathrm{c}$ continuously tune the properties because their electronic states can be continuously controlled by changing compositions. ${ }^{20}$ However, the development of solid-solution alloy NPs has long been limited by the immiscibility of the constituents, because most of the metal combinations are immiscible in the bulk state. $^{21}$ Although several new solid-solution alloy NPs in immiscible systems such as $\mathrm{Ag}-\mathrm{Rh}^{22}$ and $\mathrm{Pd}-\mathrm{Ru}^{23}$ have been recently obtained, it is still challenging to synthesize solidsolution alloy NPs, particularly those that have a large gap of reduction potential between the constituent metals.

The key point in the synthesis of these solid-solution noble alloy NPs is the concurrent reduction of metal precursors. ${ }^{\mathbf{2 4 , 2 5}}$ If the two kinds of metal ions are not reduced simultaneously, phase-separated NPs, such as core-shell or segregated types, would be obtained. ${ }^{26}$ However, it is not easy to simultaneously reduce two kinds of noble metal ions that have a large gap of reduction potential causing a remarkable difference in reduction speed, such as $\mathrm{Au}$ and $\mathrm{Ru}$ which have the largest gap among noble metals $\left(\mathrm{Ru}^{3+}+3 \mathrm{e}^{-} \rightleftharpoons \mathrm{Ru}, E^{\circ}=0.455 \mathrm{~V} v\right.$ s. $\mathrm{Au}^{3+}+3 \mathrm{e}^{-} \rightleftharpoons \mathrm{Au}$, $E^{\circ}=1.498 \mathrm{~V}$, as shown in Table $\left.\mathrm{S} 1 \dagger^{27}\right) .^{24,25}$

$\mathrm{Ru}$ is one of the best known highly active catalysts for the oxygen evolution reaction (OER). ${ }^{28,29}$ However, Ru catalysts are generally unstable in acidic solutions because $\mathrm{Ru}$ is easily oxidized in the working potential range of the OER. ${ }^{30-32} \mathrm{Au}$ is known as the most stable metal and is used to improve the stability of metal catalysts. ${ }^{33-35}$ Actually, it is recently reported that even phase separated $\mathrm{Au}-\mathrm{Ru}$ NPs show an enhanced OER performance. ${ }^{36}$ Therefore, the alloying of $\mathrm{Au}$ and $\mathrm{Ru}$ at the atomic level could be an effective way to improve the catalytic 
performance of Ru OER catalysts. In general, varying the composition of the solid-solution alloy has a great significance on its properties because the electronic structure of the alloy can be changed with its composition. ${ }^{22,23,37}$ Thus, it is interesting and challenging to create $\mathrm{Au}_{x} \mathrm{Ru}_{1-x}$ solid-solution alloy NPs over the entire composition range and to further systematically investigate their OER catalytic performance.

In this study, we carefully chose metal precursors with suitable ligands to overcome the limitation of the reduction potential difference and successfully obtained AuRu solidsolution alloy NPs over the entire composition range for the first time, although $\mathrm{Au}$ and $\mathrm{Ru}$ are immiscible throughout the entire composition range in the bulk state even at high temperatures up to their melting points (Fig. $\mathrm{S} 1 \dagger){ }^{38} \mathrm{We}$ also examined the OER catalytic performance of $\mathrm{Au}_{x} \mathrm{Ru}_{1-x}$ NPs and found that the activity continuously changed with composition and the alloy NPs exhibited an enhanced performance compared with pure $\mathrm{Au}$ and $\mathrm{Ru}$.

\section{Results and discussion}

\section{Synthesis and characterization}

To synthesize the $\mathrm{Au}_{x} \mathrm{Ru}_{1-x}$ solid-solution NPs, we controlled the reduction speed of the precursors by choosing appropriate coordinating ligands of the metal precursors because the ligands can profoundly affect the ions' stability and reduction potential, and thus their reduction kinetics can be desirably tuned. ${ }^{25}$ Potassium pentachloronitrosylruthenate(II) $\left(\mathrm{K}_{2} \mathrm{Ru}(\mathrm{NO}) \mathrm{Cl}_{5}\right)^{39}$ and hydrogen tetrabromoaurate(III) hydrate $\left(\mathrm{HAuBr}_{4} \cdot n \mathrm{H}_{2} \mathrm{O}\right)$ were chosen as metal precursors to form the solid-solution alloy NPs. $\mathrm{Au}_{x} \mathrm{Ru}_{1-x}$ solid-solution NPs were synthesized using a polyol reduction method. First, the precursors were dissolved in $10 \mathrm{ml}$ diethylene glycol (DEG) with an appropriate molar ratio. Then, the metal precursor solution was slowly dropped into $100 \mathrm{ml}$ ethylene glycol (EG) solution containing $444 \mathrm{mg}$ poly(vinylpyrrolidone) (PVP) at $190{ }^{\circ} \mathrm{C}$. The temperature of the solution was maintained at $190{ }^{\circ} \mathrm{C}$ during the dropping process. The NPs were separated by centrifugation after cooling to room temperature. The details of the experimental conditions are described in the ESI. $\dagger$

The prepared samples were characterized by transmission electron microscopy (TEM) (Fig. S2 $\dagger$ ). The mean diameters of the $\mathrm{Au}_{x} \mathrm{Ru}_{1-x}(x=0.1,0.3,0.5,0.7$, and 0.9) NPs were determined from the TEM images to be $6.6 \pm 1.4,15.7 \pm 2.9,15.4 \pm$ $2.5,15.3 \pm 2.3$, and $15.3 \pm 2.7 \mathrm{~nm}$, respectively. The particle size of $\mathrm{Au}_{0.1} \mathrm{Ru}_{0.9}$ is relatively smaller compared to other compositions. This may be related to the nature of $\mathrm{Ru}$. X-ray fluorescence (XRF) and energy-dispersive X-ray (EDX) analyses confirmed the atomic ratios of $\mathrm{Au}$ and $\mathrm{Ru}$ in the prepared NPs (Table $\mathrm{S} 2 \dagger$ ). These results are consistent with the nominal ratios of the metal precursors used in the synthesis.

To clarify the structure of the obtained AuRu NPs, high-angle annular dark-field scanning TEM (HAADF-STEM) and EDX elemental mapping of $\mathrm{Au}$ and $\mathrm{Ru}$ were carried out. HAADFSTEM images and the maps of $\mathrm{Au}$ and $\mathrm{Ru}$ elemental distribution on the obtained $\mathrm{Au}_{x} \mathrm{Ru}_{1-x}$ NPs are shown in Fig. 1a-e and $\mathrm{f}-$

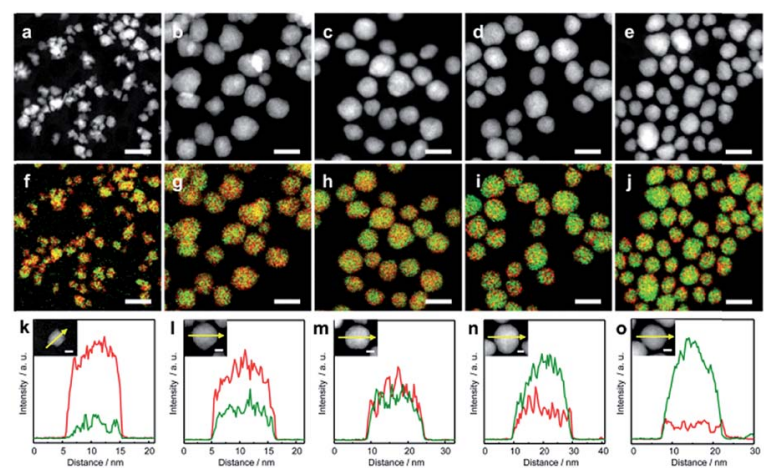

Fig. 1 High-angle annular dark-field scanning transmission electron microscopy (HAADF-STEM) images of (a) $\mathrm{Au}_{0.1} \mathrm{Ru}_{0.9}$, (b) $\mathrm{Au}_{0.3} \mathrm{Ru} \mathrm{u}_{0.7}$, (c) $A u_{0.5} R u_{0.5}$, (d) $A u_{0.7} R u_{0.3}$, and (e) $A u_{0.9} R u_{0.1}$ NPs. (f) - (j) are the corresponding overlay images of the Ru- $L$ and $A u-L$ STEM energy-dispersive X-ray (EDX) maps of (a)-(e). (k)-(o) are the EDX line profiles of the NPs along the arrows shown in the inset figures. Au and Ru are indicated in green and red colors, respectively. The scale bars shown in (a)-(j) and the inset figures of (k)-(o) are 20 and $5 \mathrm{~nm}$, respectively.

$\mathrm{j}$, respectively. Au-L and Ru-L STEM-EDX maps of $\mathrm{Au}_{x} \mathrm{Ru}_{1-x} \mathrm{NPS}$ are separately shown in Fig. S3. $\dagger$ These results give direct evidence of the homogeneous distribution of $\mathrm{Au}$ and $\mathrm{Ru}$ atoms in each particle. The typical EDX line scan profiles shown in Fig. 1k-O also demonstrate that $\mathrm{Au}$ and $\mathrm{Ru}$ atoms are well distributed in the particles, and the metal composition of the particles gradually changes from Ru-rich to Au-rich. These results show the formation of $\mathrm{Au}_{x} \mathrm{Ru}_{1-x}$ solid-solution alloy NPs over the entire composition range.

The crystal structure of the obtained AuRu NPs was investigated by synchrotron powder X-ray diffraction (XRD) analysis at BL02B2, SPring-8. ${ }^{40}$ The XRD patterns of $\mathrm{Au}_{x} \mathrm{Ru}_{1-x}$ NPs gradually change from face-centered cubic (fcc) to hexagonal closedpacked (hcp) patterns with increasing amounts of Ru (Fig. 2a). We then performed Rietveld refinement on each pattern of the alloy NPs (Fig. 2b, c and S4-S7†). The best fit of $\mathrm{Au}_{0.5} \mathrm{Ru}_{0.5}$ was obtained with two components of fcc and hcp (Fig. 2c). The lattice constant of the fcc component was calculated to be 3.960(6) $\AA$, which is smaller than that of Au NPs $(a=4.077(1) \AA$, Fig. S8 $\dagger$ ). For the hcp component, the lattice constants were 2.795(1) and 4.435(3) $\AA$ for $a_{\mathrm{hcp}}$ and $c_{\mathrm{hcp}}$, which were larger than those of Ru NPs $(a=2.709(5)$ and $c=4.307(8) \AA$, Fig. S9†). As both hcp and fcc are close-packed structures, the lattice parameter $a_{\mathrm{fcc}}$ in a fcc structure is nearly $\sqrt{ } 2 a_{\mathrm{hcp}}$ in an hcp structure. Given that the lattice constant follows Vegard's law, ${ }^{\mathbf{4 1}}$ the $\mathrm{Au}: \mathrm{Ru}$ compositions of the fcc and the hcp phases were estimated to be $0.52: 0.48$ and $0.50: 0.50$, which are similar to the results of EDX and XRF analyses. These results strongly suggest that $\mathrm{Au}_{0.5} \mathrm{Ru}_{0.5}$ NPs contain two phases; however, both phases are solid-solution structures with the same composition. The lattice constants of $\mathrm{Au}_{x} \mathrm{Ru}_{1-x}$ NPs increased linearly with increasing $\mathrm{Au}$ content $(x)$ as estimated by Rietveld refinement (Fig. 2b). The linear correlation between the composition and the lattice constant follows Vegard's law, which also confirmed the formation of the solid-solution AuRu alloy over the entire composition range. 

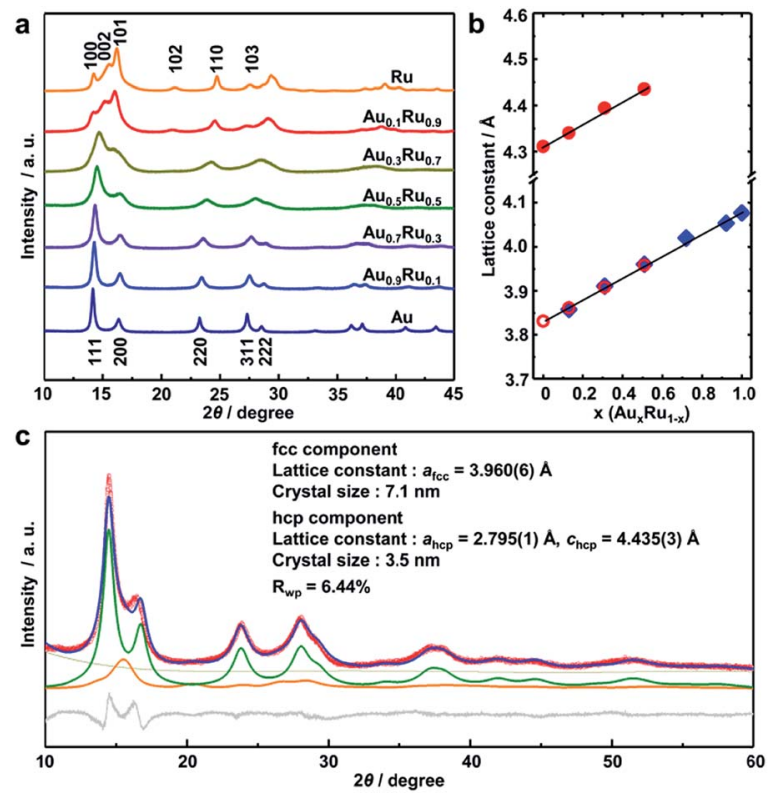

Fig. 2 (a) The synchrotron powder XRD patterns $\left(2 \theta=10-45^{\circ}\right)$ of $\mathrm{Au}_{x} R \mathrm{u}_{1-x} \mathrm{NPs}$ at $303 \mathrm{~K}$. The radiation wavelength was $0.58068(1) \AA$. (b) Dependence of the lattice constant on the metal composition in $\mathrm{Au}_{x} \mathrm{Ru}_{1-x} \mathrm{NPs}$. $O$ (red), $\boldsymbol{\Theta}$ (red), and (blue) indicate the lattice constant $a_{\mathrm{hcp}}$ and $c_{\mathrm{hcp}}$ of the hcp component and $a_{\mathrm{fcc}}$ of the fcc component, respectively. (c) The diffraction pattern of $\mathrm{Au}_{0.5} \mathrm{Ru}_{0.5} \mathrm{NPs}$ (red circles) at $303 \mathrm{~K}$ and the calculated profile (blue line) by Rietveld refinement. The profiles of the difference, background, and the fcc and hcp components are shown as gray, dark yellow, green and orange lines, respectively.

\section{Catalytic properties}

The electrocatalytic OER activity of $\mathrm{Au}_{x} \mathrm{Ru}_{1-x}$ NPs was investigated in a $0.05 \mathrm{M} \mathrm{H}_{2} \mathrm{SO}_{4}$ solution in a standard three-electrode system with a $\mathrm{Pt}$ wire and an $\mathrm{Ag} / \mathrm{AgCl}(3.5 \mathrm{M} \mathrm{NaCl})$ electrode as the counter and reference electrodes, respectively. The synthesized NPs were first loaded on carbon black (VXC 72R) with $20 \mathrm{wt} \%$ metal (Fig. S10†). The catalysts were uniformly cast onto a rotating disk electrode for recording $i R$-corrected OER polarization curves at a scan rate of $5 \mathrm{mV} \mathrm{s}^{-1}$. The working electrode was continuously rotated at $1600 \mathrm{rpm}$ during the measurements. The $\mathrm{Au}$ and $\mathrm{Ru}$ catalysts were also measured as a reference.

Fig. 3a shows the linear sweep voltammetry (LSV) curves of the $\mathrm{Au}_{x} \mathrm{Ru}_{1-x}$ catalysts. The current densities of each catalyst at potentials of 1.5 and $1.6 \mathrm{~V}$ are shown in Fig. $3 \mathrm{~b}$ and c. For the Ru catalyst, the current density has the highest value at around $1.5 \mathrm{~V}$, but gradually reduces after that, which is caused by the dissolution of $\mathrm{Ru}$ with the potential increasing. ${ }^{30-32}$ The $\mathrm{Au}$ catalyst does not show obvious catalytic activity. ${ }^{42}$ The $\mathrm{Au}_{x} \mathrm{Ru}_{1-x}$ catalysts demonstrated the composition dependence of the catalytic performance. With increasing $\mathrm{Ru}$ content, the current density becomes higher. More importantly, Au is inactive for the OER; nevertheless, $\mathrm{Au}_{0.3} \mathrm{Ru}_{0.7}$ and $\mathrm{Au}_{0.1} \mathrm{Ru}_{0.9}$ catalysts show higher activity than $\mathrm{Ru}$ at $1.5 \mathrm{~V}$. The current densities of the $\mathrm{Au}_{x} \mathrm{Ru}_{1-x}$ catalysts continuously increase with the potential increasing and are higher than that of the Ru catalyst at $1.6 \mathrm{~V}$.
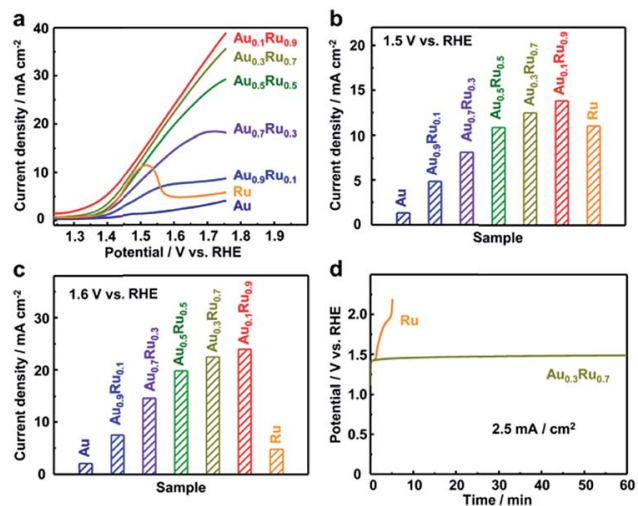

Fig. 3 (a) Linear sweep voltammetry (LSV) polarization curves of the OER catalyzed by $\mathrm{Au}_{x} \mathrm{Ru}_{1-x}$ catalysts. The current density of each catalyst at potentials of (b) $1.5 \mathrm{~V}$ and (c) $1.6 \mathrm{~V}$. (d) Chronopotentiometry curves of the $\mathrm{Au}_{0.3} \mathrm{Ru}_{0.7}$ catalyst compared to the $\mathrm{Ru}$ catalyst at a constant current density of $2.5 \mathrm{~mA} \mathrm{~cm}^{-2}$ for $1 \mathrm{~h}$. All the tests were performed in an Ar-saturated $0.05 \mathrm{M} \mathrm{H}_{2} \mathrm{SO}_{4}$ solution at a scan rate of $5 \mathrm{mV} \mathrm{s}^{-1}$. All the polarization curves were collected with $i R$-correction.

This confirms the stability improvement of the $\mathrm{Au}_{x} \mathrm{Ru}_{1-x}$ catalysts. We further investigated the stability of $\mathrm{Au}_{0.3} \mathrm{Ru}_{0.7}$ and $\mathrm{Au}_{0.1} \mathrm{Ru}_{0.9}$ catalysts by chronopotentiometry tests at a constant current density of $2.5 \mathrm{~mA} \mathrm{~cm}^{-2}$ for $1 \mathrm{~h}$ (Fig. $3 \mathrm{~d}$ and $\left.\mathrm{S} 11 \dagger\right)^{43,44}$ The curves show the potential change at a current density of 2.5 $\mathrm{mA} \mathrm{cm}{ }^{-2}$. The potential of the Ru catalyst quickly changed from 1.4 to above $2.0 \mathrm{~V}$ in $5 \mathrm{~min}$, essentially losing all its activity. In contrast, the $\mathrm{Au}_{0.3} \mathrm{Ru}_{0.7}$ and $\mathrm{Au}_{0.1} \mathrm{Ru}_{0.9}$ catalysts showed a much slower deactivation during the stability test. From these results, it can be concluded that the alloy catalysts show much higher stability than the pure Ru catalyst.

We then investigated the structures of the $\mathrm{Ru}, \mathrm{Au}_{0.3} \mathrm{Ru}_{0.7}$ and $\mathrm{Au}_{0.1} \mathrm{Ru}_{0.9}$ catalysts after the stability test by TEM, STEM-EDX and X-ray absorption near-edge structure (XANES). From TEM observations, we found that there were no Ru NPs on the carbon in the $\mathrm{Ru} / \mathrm{C}$ catalyst after the test due to the rapid oxidation and dissolution of $\mathrm{Ru}$ (Fig. S12a $\dagger$ ). ${ }^{30-32}$ In contrast, a large amount of $\mathrm{Au}_{0.3} \mathrm{Ru}_{0.7}$ or $\mathrm{Au}_{0.1} \mathrm{Ru}_{0.9}$ NPs remained on the carbon support (Fig. S12b and $\mathrm{c} \dagger$ ). We further analyze the structure of the alloy catalysts after the OER with $\mathrm{Au}_{0.3} \mathrm{Ru}_{0.7}$. HAADF- and bright field (BF)-STEM images (Fig. 4a-d) show the comparison of the alloy structures before and after the stability test. Both of the particles show the same fcc lattice and $\{111\}$ interplanar spacing, indicating that the metallic structure of alloy NPs was mostly retained. However, a thin amorphous layer was observed on the alloy surface after the stability test. STEM-EDX analysis confirmed the good distributions of $\mathrm{Au}$ and $\mathrm{Ru}$ in the NPs (Fig. 4e-h, S13 and S14 $\dagger$ ). We further investigated the structure of the catalysts with XANES. The $\mathrm{Au} \mathrm{L}_{3}$-edge and $\mathrm{Ru}$ K-edge spectra confirmed that the original alloy structure was maintained after the stability test, and indicated that the thin amorphous layer on the alloy surface would be $\mathrm{RuO}_{x}$ (Fig. 4i-j).

To elucidate the enhancement of the catalytic performance, the change in the electronic structure caused by atomic level alloying of Au and Ru was investigated by XPS (Fig. S14, Table $\mathrm{S} 3 \dagger)$. The Au $4 \mathrm{f}$ peaks of the alloys shifted to higher energy with 

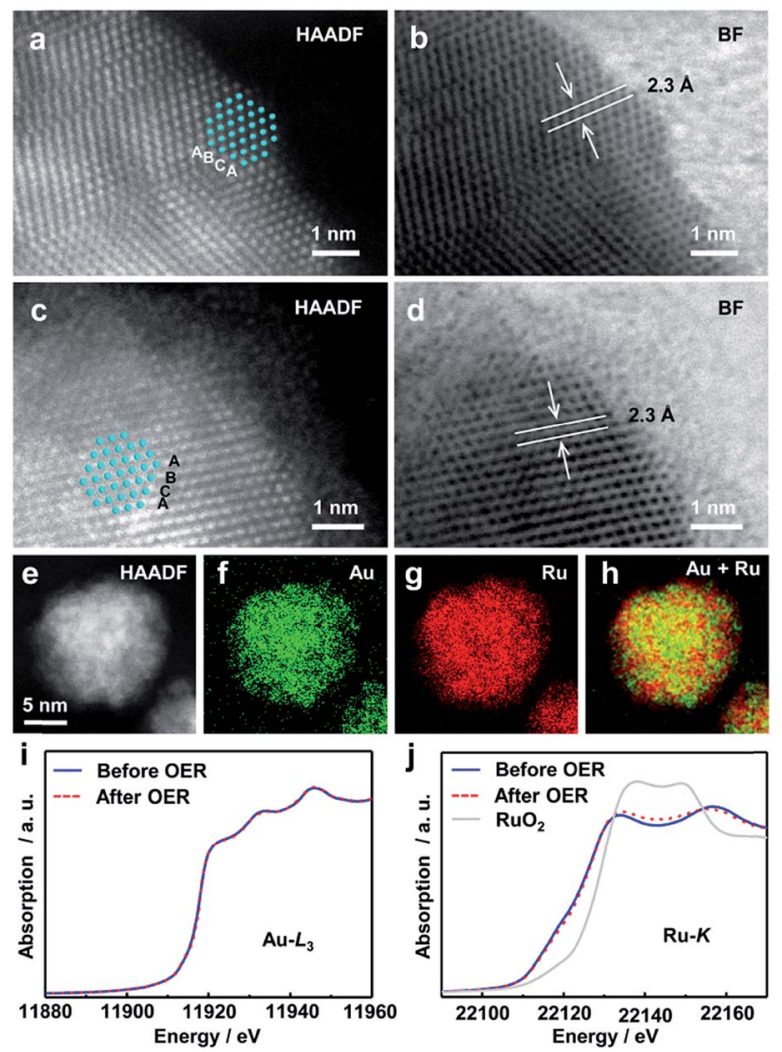

Fig. 4 HAADF-STEM images of the $\mathrm{Au}_{0.3} \mathrm{Ru}_{0.7}$ catalyst before (a) and after (c) the chronopotentiometric stability measurement. (b) and (d) BF images of the NPs in (a) and (c). (e) HAADF-STEM image of the $A u_{0.3} R u_{0.7}$ catalyst after the stability measurement, (f) - (h) Au- $L$ (green), $R u-L$ (red), overlay (Ru + Au) STEM-EDX maps of NPs in (e). Au $L_{3}$-edge (i) and Ru K-edge (j) XANES spectra of the $\mathrm{Au}_{0.3} \mathrm{Ru}_{0.7}$ catalyst before and after OER stability measurement.

increasing $\mathrm{Ru}$ content. By contrast, with the $\mathrm{Au}$ content increasing, the $\mathrm{Ru} 3 \mathrm{p}$ peaks of the alloys shifted to a lower energy. These results indicate electron transfer from $\mathrm{Au}$ to $\mathrm{Ru}$ in alloy NPs. According to the mechanism of the OER in an acid solution (Table $\mathrm{S} 4 \dagger$ ), the formation of intermediate oxygen species on the surface of the catalyst (e.g., * ${ }^{*} \mathrm{OH},{ }^{*} \mathrm{O}$, and ${ }^{*} \mathrm{OOH}$; * represent active sites on the metal surface) is a key step for the OER process. ${ }^{45}$ These steps would be significantly affected by the change in the electronic structure of the catalyst. Thus, the change of the electronic structure in $\mathrm{Au}_{x} \mathrm{Ru}_{1-x} \mathrm{NPs}$ could lead to better balance between adsorption and dissociation energies for oxygen species and further enhance the catalytic activity. ${ }^{46,47}$ At the same time, the electron transfer from $\mathrm{Au}$ to $\mathrm{Ru}$ in $\mathrm{Au}_{x} \mathrm{Ru}_{1-x}$ NPs could suppress the oxidation of $\mathrm{Ru}$, which would be one of the origins of the enhancement in the stability of the $\mathrm{Au}_{x} \mathrm{Ru}_{1-x}$ alloy catalysts. Therefore, the alloying of $\mathrm{Ru}$ with $\mathrm{Au}$ improves the activity and stability of Ru as the OER catalyst in acid solutions.

\section{Conclusions}

In summary, we synthesized and characterized $\mathrm{Au}_{x} \mathrm{Ru}_{1-x}$ solidsolution NPs over the whole composition range for the first time, where $\mathrm{Au}$ and $\mathrm{Ru}$ have the largest gap in reduction potential among noble metals and are completely immiscible even at high temperatures up to their melting points in the bulk state. STEM-EDX and PXRD results demonstrated that Au and $\mathrm{Ru}$ were randomly and homogeneously distributed in a single NP. The alloy catalysts showed an enhanced catalytic performance compared with Ru which is known as one of the best monometallic OER catalysts. By alloying $\mathrm{Ru}$ with $\mathrm{Au}$, the stability of the catalyst was significantly improved. Our present work provided not only an effective OER catalyst that could work in an acidic environment, but also triggered the development of undiscovered solid-solution alloy NPs from immiscible noble metals.

\section{Conflicts of interest}

There are no conflicts to declare.

\section{Acknowledgements}

This research was supported by the ACCEL program grant number JPMJAC1501, Japan Science and Technology Agency (JST). STEM observations were performed as part of a program conducted by the Advanced Characterization Nanotechnology Platform sponsored by the MEXT of the Japanese Government. Synchrotron XRD measurements were carried out at SPring-8 under proposal No. 2015A1319, 2015B1339, and 2016A1483. Xray absorption measurements were carried out at SPring-8 under proposal No. 2018B1728. The activities of the INAMORI Frontier Research Center, Kyushu University are supported by KYOCERA Corporation.

\section{Notes and references}

1 J. P. Wilcoxon and B. L. Abrams, Chem. Soc. Rev., 2006, 35, 1162.

2 Y. Xia, Y. Xiong, B. Lim and S. E. Skrabalak, Angew. Chem., Int. Ed., 2009, 48, 60.

3 J. Zhang and C. M. Li, Chem. Soc. Rev., 2012, 41, 7016.

4 H. You, S. Yang, B. Ding and H. Yang, Chem. Soc. Rev., 2013, 42, 2880.

5 K. Aika, T. Takano and S. Murata, J. Catal., 1992, 136, 126.

6 M. Kitano, Y. Inoue, Y. Yamazaki, F. Hayashi, S. Kanbara, S. Matsuishi, T. Yokoyama, S. W. Kim, M. Hara and H. Hosono, Nat. Chem., 2012, 4, 934.

7 M. Kitano, S. Kanbara, Y. Inoue, N. Kuganathan, P. V. Sushko, T. Yokoyama, M. Hara and H. Hosono, Nat. Commun., 2015, 6, 6731.

8 H. S. Gandhi, G. W. Graham and R. W. McCabe, J. Catal., 2003, 216, 433.

9 M. Bowker, Chem. Soc. Rev., 2008, 37, 2204.

10 C. Della Pina, E. Falletta, L. Prati and M. Rossi, Chem. Soc. Rev., 2008, 37, 2077.

11 O. Casanova, S. Iborra and A. Corma, J. Catal., 2009, 265, 109.

12 H. Miyamura, T. Yasukawa and S. Kobayashi, Green Chem., 2010, 12, 776. 
13 B. S. Takale, M. Bao and Y. Yamamoto, Org. Biomol. Chem., 2014, 12, 2005.

14 S. Alayoglu, A. U. Nilekar, M. Mavrikakis and B. Eichhorn, Nat. Mater., 2008, 7, 333.

15 K. Kusada, D. Wu, T. Yamamoto, T. Toriyama, S. Matsumura, W. Xie, M. Koyama, S. Kawaguchi, Y. Kubota and H. Kitagawa, Chem. Sci., 2019, 10, 652.

16 D. Wang and Y. Li, Adv. Mater., 2011, 23, 1044.

17 Y. Yamauchi, A. Tonegawa, M. Komatsu, H. Wang, L. Wang, Y. Nemoto, N. Suzuki and K. Kuroda, J. Am. Chem. Soc., 2012, 134, 5100.

18 Y. C. Hsieh, Y. Zhang, D. Su, V. Volkov, R. Si, L. Wu, Y. Zhu, W. An, P. Liu, P. He, S. Ye, R. R. Adzic and J. X. Wang, Nat. Commun., 2013, 4, 2466.

19 Y. Yao, Z. Huang, P. Xie, S. D. Lacey, R. J. Jacob, H. Xie, F. Chen, A. Nie, T. Pu, M. Rehwoldt, D. Yu, M. R. Zachariah, C. Wang, R. Shahbazian-Yassar, J. Li and L. Hu, Science, 2018, 359, 1489.

20 H. Kobayashi, K. Kusada and H. Kitagawa, Acc. Chem. Res., 2015, 48, 1551.

21 H. Okamoto, Desk Handbook: Phase Diagrams for Binary Alloys, ASM International, Ohio, USA 2010.

22 K. Kusada, M. Yamauchi, H. Kobayashi, H. Kitagawa and Y. Kubota, J. Am. Chem. Soc., 2010, 135, 15896.

23 K. Kusada, H. Kobayashi, R. Ikeda, Y. Kubota, M. Takata, S. Toh, T. Yamamoto, S. Matsumura, N. Sumi, K. Sato, K. Nagaoka and H. Kitagawa, J. Am. Chem. Soc., 2014, 136, 1864.

24 K. Kusada and H. Kitagawa, Adv. Mater., 2016, 28, 1129.

25 K. D. Gilroy, A. Ruditskiy, H. C. Peng, D. Qin and Y. Xia, Chem. Rev., 2016, 116, 10414.

26 D. Wu, Z. Zheng, S. Gao, M. Cao and R. Cao, Phys. Chem. Chem. Phys., 2012, 14, 8051.

27 P. Vanýsek, in CRC Handbook of Chemistry and Physics, ed. D. R. Lide, Taylor \& Francis, Boca Raton, Florida, USA, 83rd edn, 2002.

28 Y. Jiao, Y. Zheng, M. Jaroniec and S. Z. Qiao, Chem. Soc. Rev., 2015, 44, 2060.

29 S. Cherevko, S. Geiger, O. Kasian, N. Kulyk, J. Grote, A. Savan, B. R. Shrestha, S. Merzlikin, B. Breitbach, A. Ludwig and K. J. J. Mayrhofer, Catal. Today, 2016, 262, 170.

30 T. Reier, M. Oezaslan and P. Strasser, ACS Catal., 2012, 2, 1765.
31 Y. Lee, J. Suntivich, K. J. May, E. E. Perry and Y. Shao-Horn, J. Phys. Chem. Lett., 2012, 3, 399.

32 N. T. Suen, S. F. Hung, Q. Quan, N. Zhang, Y. J. Xu and H. M. Chen, Chem. Soc. Rev., 2017, 46, 337.

33 J. Zhang, K. Sasaki, E. Sutter and R. R. Adzic, Science, 2007, 315, 220.

34 X. Sun, D. Li, Y. Ding, W. Zhu, S. Guo, Z. L. Wang and S. Sun, J. Am. Chem. Soc., 2014, 136, 5745.

35 D. Wang, S. Liu, J. Wang, R. Lin, M. Kawasaki, E. Rus, K. E. Silberstein, M. A. Lowe, F. Lin, D. Nordlund, H. Liu, D. A. Muller, H. L. Xin and H. D. Abruna, Nat. Commun., 2016, 7, 11941.

36 L. Gloag, T. M. Benedetti, S. Cheong, Y. Li, X. Chan, L. Lacroix, S. L. Y. Chang, R. Arenal, I. Florea, H. Barron, A. S. Barnard, A. M. Henning, C. Zhao, W. Schuhmann, J. J. Gooding and R. D. Tilley, Angew. Chem., Int. Ed., 2018, 57, 10241.

37 D. Xu, S. Bliznakov, Z. Liu, J. Fang and N. Dimitrov, Angew. Chem., Int. Ed., 2010, 49, 1282.

38 H. Okamoto and T. B. Massalski, J. Phase Equilib., 1984, 5, 388.

39 J. T. Veal and D. J. Hodgson, Acta Crystallogr., Sect. B: Struct. Crystallogr. Cryst. Chem., 1972, 28, 3525.

40 S. Kawaguchi, M. Takemoto, K. Osaka, E. Nishibori, C. Moriyoshi, Y. Kubota, Y. Kuroiwa and K. Sugimoto, Rev. Sci. Instrum., 2017, 88, 085111.

41 A. R. Denton and N. W. Ashcroft, Phys. Rev. A: At., Mol., Opt. Phys., 1991, 43, 3161.

42 Z. Zhuang, W. Sheng and Y. Yan, Adv. Mater., 2014, 26, 3950.

43 H. N. Nong, H. S. Oh, T. Reier, E. Willinger, M. G. Willinger, V. Petkov, D. Teschner and P. Strasser, Angew. Chem., Int. Ed., 2015, 54, 2975.

44 Y. Pi, N. Zhang, S. Guo, J. Guo and X. Huang, Nano Lett., 2016, 16, 4424.

45 J. Rossmeisl, A. Logadottir and J. K. Nørskov, Chem. Phys., 2005, 319, 178.

46 H. S. Oh, H. N. Nong, T. Reier, A. Bergmann, M. Gliech, J. F. de Araujo, E. Willinger, R. Schlogl, D. Teschner and P. Strasser, J. Am. Chem. Soc., 2016, 138, 12552.

47 J. Kim, P. C. Shih, K. C. Tsao, Y. T. Pan, X. Yin, C. J. Sun and H. Yang, J. Am. Chem. Soc., 2017, 139, 12076. 